\title{
Films Can Change Your Life (Interview)
}

\author{
By Marin Karmitz
}

Fall 1998 Issue of KINEMA

LIGHT, rebellion, love, equality, cinema, democracy: the words that adorn the frontispiece of the latest "cinema venue" created by Marin Karmitz, in Paris, more or less sum up the independent producer's ambitious and quasi-militant concept of cinema; indeed, Karmitz is someone who puts his passion at the service of creative film directors the world over. He is a producer, distributor both in France and abroad, and also runs a number of cinemas in Paris; after many years as a marginalised figure, he is now at the very heart of the French film-making industry.

This interview, conducted by Anne Rapin, was originally published in Label France No. 31, April 1998. ${ }^{(1)}$

Label France: People send you a thousand scripts a year. What criteria do you use to decide which films to produce in any given year?

Marin Karmitz: There are several ways of looking at what a producer does. Personally, I prefer not to work on the premise that a film is a commercial venture but to rely instead on my instinct, on wanting to work with a particular director and to produce a script. Only then do I try and secure the means to make the film. Let's say my approach is much more like that of a publisher or dealer; after all, I have to ensure not only that the film can be made but also that it exists for the public, in other words promote it, secure its distribution and sale, abroad in particular.

Which explains the many strings to your bow...

True -- I am after all a producer, a distributor both in France and abroad, a cinema operator and also a licenser, in other words I own a whole catalogue of works, just like any good publishing company. The reason I have all these other occupations is to make sure that the production side of it goes well, which is after all at the very core of MK2. It's a novel approach, especially in France, where traditionally the big companies have come from the distribution side and gradually moved upstream towards production; I, for my part, have come from production and moved downstream towards distribution.

As a producer and operator, how do you combine profitability with the risk-taking involved with the more daring works that are not necessarily mainstream?

Unlike appointed or executive producers, I do not have to rely on financing from industry or banking when deciding whether or not to make a film. I have also tried to reduce as much as possible any links that made me dependent on distributors, whether in cinema or television. In France, up until the end of the eighties, a film' s profitability was decided essentially by how well it did at the box office. With the boom in public-sector, private and pay-TV stations and their demand for programmes and especially films, TV channels have become the main source of financing for the film industry.

TV stations tend to produce whatever films they believe correspond to their prime-time viewers' expectations. This approach is diametrically opposed to what one might term cinematographic creativity. It is obvious that if you want to make creative or "indie" movies, you cannot depend on such constraints.

You have always been a great supporter of the local cinema and a pioneer in re-establishing cinemas throughout Paris, most recently with the founding of a cinema theatre in the 19th arrondissement and, soon, with your big project for a City of Image and Sound near the Bibliothèque nationale de France. What is the driving force behind these policies?

I opened my first cinema at La Bastille in 1974, a move which, already then, went against the general trend since it was a very working-class area. Indeed, it had been abandoned by classic cinema, and the object, after all, was to screen a different kind of film, in the original language, which, I was told, simply did not appeal to mass audiences. At the time, there were only two places in Paris where you could go and watch this type of film, namely the Quartier Latin and the Champs-Elysées.

I set up a venue -- referred to at the time as a counter-culture venue -- with three cinemas but also a library, a 
place to meet and an exhibition gallery, used for staging various events. The venue was very quickly adopted by audiences. Consequently, I opened up other cinemas, ${ }^{(2)}$ again for films in the original language, which led to an explosion of the genre in Paris and encouraged new audiences used to and, subsequently, devoted to original language films. I am very proud of that experience. It is very much in tune with the idea of safeguarding the film industry as you can only truly respect a film if you show it in its original language.

The idea of turning cinemas into a living space, somewhere capable of transforming abandoned or derelict city areas by injecting happiness and new life, making them into a place of exchange, is something I have not been able to do at all my cinema theatres for architectural reasons, but which I did achieve recently in the 19th arrondissement. I found a remarkable place there, disused boat hangars which we turned into a highly original venue, on the edge of the Canal de la Villette, with six cinema screens equipped with the state of the art, and two restaurants, ${ }^{(3)}$ in an area that did not have a single cinema left, after twenty or so in the sixties.

And it's been a fabulous success in an area that is extremely working class, where screening original language, art house films seemed like sheer madness. In a single year these cinemas have attracted 400,000 spectators, far more than we expected. And perhaps even more importantly, this area used to be a no-go area, synonymous with drugs and insecurity in Paris; now it has once again become fashionable. The drugs have gone, people have started going out again in the evening, they have new confidence in the area and are proud to live there. A certain approach, mindful of people and creative output, can very well transform life -- for me, that's a very strong symbol.

And what about your project for a City of Image and Sound in the 13th arrondissement?

It's the same idea. In an area currently in complete upheaval, which does not exist as such, an area that is developing around the Bibliothèque nationale de France, we have put in place a rather impressive project that posed a fascinating architectural puzzle. How, in a place already recognised worldwide as an historical site, do you go about making your mark not only without having a devastating effect but also by trying to be the binding link between the site and the area itself?

It's what we have tried to set up with the aid of architects Jean-Michel Wilmotte and Frédéric Namur, through a project of 13-14 screens, a very large restaurant, various cultural venues. So, in a sense, it's both a project of architectural creation and of integration into the city, and also a gamble on a new district. And I find this way of building the future through the cinema and film simply wonderful. ${ }^{(4)}$

What is your opinion of the trend, particularly in France, towards multiplex cinemas, which has helped to boost the number of cinema-goers but is also accused of seriously reducing the films on offer by screening virtually nothing other than box office hits?

I feel the question of multiplex cinemas is very much like the situation that exists between local high street shops and hypermarkets. Ideally, you would need to preserve the right balance between the two in order not to destroy the social links, a result of which are the crises we see flaring up in all cities and large council estates. Cinema contributes to quality of life, to happiness and to the possibilities of living together as a community. That's why I'm so totally dedicated to preserving local venues.

But you also get multiplex cinemas in town centres...

I'm not someone who excludes for the sake of it, and I believe that local cinemas should be able to co-exist alongside a certain number of multiplexes. It is a fact, however, that the trend we are witnessing is the destruction, that is to say exclusion, of local cinemas by multiplexes rather than the other way round. And that's much more serious. What's more, in France, we are also seeing "dumping" practices by out-of-town cinemas that simply smash prices. This shows total contempt for the film industry itself since cinema receipts also filter back to the producer and the film-makers. It amounts to destroying the means of production in order to develop the means of marketing and distribution. And that's particularly serious.

Finally, in order to sustain such a large number of screens, these multiplex centres show mostly American films, and not even in the original language. This policy is creating a disparity between the city centres and the outlying suburbs, giving rise to a two-tier culture, with one type of cinema for the poor and one for the rich. Films that cater for the rich are those where there are still traces of independent creative output while films for the poor have become the "opium of the masses," a policy of dumbing-down based on special 
effects, gratuitous violence, contempt for law and order... I think that's very dangerous. For my part, I'm going to build a mega-complex, and I'll try and show that you can use this modern means of distribution in other ways, provided you observe a certain ethical approach.

Do you think it's up to the government to legislate in order to preserve the pluralism of the cinema and therefore of production?

All over the world, governments are very much weakened; they no longer control economic policy or foreign policy. However, they still have a certain amount of control over national education and a number of instruments for the dissemination of culture. And I really don't see why people everywhere claim you can -- or should -- protect nature and the rain forests and yet cannot adopt the same approach for something that is just as important as trees, namely human thought and creative output. Governments should simply assume their role as representatives of their national communities, in other words act as an instrument for the preservation of cultural pluralism, which also incorporates cinemas as production and distribution sites, places where personal viewpoints are expressed.

Very often, protecting the film industry, a policy which, in France, benefits from government subsidies, is seen as something negative. Think of France's virtual isolation at the GATT talks in her struggle for a "cultural opt-out" clause. How do you explain that stakes as high as the disappearance of national film industries and the offensive or even hegemony of the American industry should have such bad press? ${ }^{(5)}$

There are lots of reasons. First of all, Europe is an ancient civilisation based on the written word, and the ruling classes, among others, have yet to become fully conscious of the rle and strength of images. You can tell with the Internet for example. Secondly, I think that European political leaders have not fully realised just how globalised communication systems have become and what effects they have. Very few people think about these problems. Few are aware of the fact that a film is not only an industrial product but also a vector of ideology that deserves closer attention. Finally, there is an overwhelming fascination with the United States and many concessions are made as a result.

I believe we are in a situation of war, a very modern war, one that is being waged through a new industry, namely the communication industry. It happens to be the United States' leading export industry; not only is it very profitable but it is also a means of exporting ideas and products, a way of life and a way of thinking. And, as in any war, there are those who resist, in this case artists from all over the world, a handful of intellectuals, some people in power, etc. Many are those who are collaborating through financial gain, such as the heads of TV stations, who buy American films at inflated prices or who co-finance the U.S. film industry with millions of dollars but stop short of making the same efforts for their own national film industry. And then of course you have a huge number of totally indifferent people.

Faced with this, you can try and launch debates, stimulate people's consciences by saying: listen, the future of cinema resides in what I call the "cinema of poor people," which exists all over the world, including the United States. It is made with a minimum of resources and yet is precisely the cinema of the future because it creates new ideas. It allows new artists, actors, technicians, etc., to exist and that is what has to be defended. That's what I'm trying to achieve through MK2.

It is not a question of challenging American cinema with European cinema, but the mass-produced and standardised cinema of Hollywood studios with the creative cinema of the whole world. My own way of fighting the American system, for example, is to produce, right now, in the United States, a wonderful film by a young director -- Claire Dolan by Lodge Kerrigan -- and to show Americans that we excel in an expertise which they have now lost.

What I'm interested in is not, like some, to finance English-language films with special effects and American stars; no, I'm interested in producing original works from all over the world, be it in Iran, the United States, Romania, Mexico or France.

How much scope do you provide for foreign films?

France plays an important role in providing world cinema with a lifeline. ${ }^{(6)}$ And it's true that I'm one of those taking part in it; after all, our open-mindedness towards film directors from all over the world is one of MK2's essential vocations. I have always been utterly convinced that the strength of French cinema stems 
only from its close relations, its alliances, its interplay with foreign film traditions. And one of the strengths of MK2 has been precisely to discover a number of them. ${ }^{(7)}$

This to-and-fro is a means of combatting exclusion, which is entirely in keeping with France's tradition as a place of acceptance and tolerance. It is something I am very proud of as, these days, you are more likely to experience the opposite, and when you're not dealing with introversion, it's usually a servile and sterile imitation of American culture.

I'm not interested in national films as such but in films that aspire to the universal. And it's important to make a distinction between what has to do with globalisation and what has to do with the universal. American cinema is global because its system of promotion and distribution is unbelievably powerful. That is not enough to make it a universal cinema. To me, universal is something that elevates and transforms, not something that debases and vilifies.

\section{Are you more optimistic or pessimistic about the future of cinema?}

I am by nature an utter pessimist but as I'm also someone who never lies down and gives up -- one contradicts the other.

\section{Notes}

1. Recommended reading: Bande à part, by Marin Karmitz, published by Grasset, 1994, Paris. 2. With 9 complexes and 44 screens scattered throughout 8 different areas of Paris, the 14-Juillet cinemas of the MK2 group represent the third largest film-screening circuit in Paris, with a market share of $15 \%$. 3 . The intriguing yet affordable menu has been entrusted to restaurateur Bruno Neveu, while the wine list has been drawn up by film director Claude Chabrol. 4. Scheduled to open in the year 2000 at the foot of the Bibliothèque nationale de France. 5. American cinema dominates around $90 \%$ of the market share in most European countries in particular, compared with 60\% in France. 6. Through various aid programmes (direct aid, Fonds Sud, Fonds ECO, joint productions, etc.). See also the Cinema feature in Label France No. 19 (March 1995). 7. The many foreign directors produced by MK2 include Britain's Ken Loach, Greece's Theo Angelopoulos, Italy's Paolo and Vittorio Taviani, Russia's Pavel Lungin, Romania's Lucian Pintilié, Poland's Krzysztof Kieslowski, Iran's Mohsen Makhmalbaf and Abbas Kiarostami. 